\title{
Effect of arc-current and spray distance on elastic modulus and fracture toughness of plasma-sprayed chromium oxide coatings
}

\author{
Simanchal KAR*, Partha Pratim BANDYOPADHYAY, Soumitra PAUL \\ Department of Mechanical Engineering, Indian Institute of Technology Kharagpur, West Bengal 721302, India \\ Received: 23 February 2017 / Revised: 13 April 2017 / Accepted: 05 May 2017 \\ (C) The author(s) 2017. This article is published with open access at Springerlink.com
}

\begin{abstract}
In this experimental study, chromium oxide powder was sprayed on a low-carbon steel substrate using the atmospheric plasma spray process. The current and standoff distances (SODs) were varied to study their effect on the fracture toughness of the coatings. Theoretically, as the arc current increases, the melting of the ceramic oxide should increase and this in turn should lead to the formation of a dense coating. However, it was observed that if the arc power is too high and because the particle size of the powder is small (approximately $30 \mu \mathrm{m}$ ), the particles tend to fly away from the plasma core. Similarly, an appropriate SOD should provide the particles with more melting time, thus resulting in a dense coating. On the other hand, a larger SOD leads to the solidification of the molten particles before the droplets can reach the substrate. All these effects may lead to substantial variation in the fracture toughness of the coating. The present paper attempts to correlate the plasma spraying parameters and microstructure of the coating with the fracture toughness and other primary coating properties.
\end{abstract}

Keywords: chromia coating; fracture toughness; plasma spray; critical plasma spray parameter; critical depth

\section{Introduction}

Surface engineering includes the study of wear, erosion, corrosion processes on the component surface, and the various methodologies to prevent them. With the help of thermal and thermo-chemical processes, surfaces can be modified to become wear and corrosion resistant while retaining the toughness and ductility of the bulk component [1]. One such example of surface engineering is a plasma sprayed chromia coating. It is extensively used as a corrosion and wear resistance coating $[2,3]$. Chromia coatings also find applications in pumps and printing rolls $[4,5]$. In general, an effective wear resistance coating is expected to possess high fracture toughness along with high hardness, good adhesion, low porosity, homogeneous structure, and uniform thickness [6]. The fracture toughness
$\left(K_{\mathrm{IC}}\right)$, is a measure of a material's resistance to brittle fracture when a crack is present $[7,8]$. For ceramic components, Evan and Charles (1976) have formulated a mathematical expression to evaluate the fracture toughness using the fracture length and Vickers indentation diagonal length as shown [9]:

$$
K_{\mathrm{IC}}=0.15 k\left(\frac{c}{a}\right)^{-3 / 2} \frac{H \sqrt{a}}{\phi}
$$

where $k=$ correction factor for ceramics $=3.2, \phi=$ constraint factor $\approx 3, H=$ Vickers hardness $(\mathrm{MPa}), a=$ half the Vickers diagonal length measured in the direction of the crack, and $c=$ sum of the length of the crack and half the Vickers diagonal length in the direction of the crack. Figure 1 shows the schematic of the Vickers indentation.

* Corresponding author: Simanchal KAR, E-mail: simanchal.kar@gmail.com 


\begin{tabular}{llll}
\multicolumn{2}{l}{ List of symbols } \\
$K_{\mathrm{IC}}:$ & Fracture toughness & $E:$ & Young's modulus \\
$k:$ & Correction factor & $P_{\mathrm{R}}{ }^{*}:$ & Load for radial crack initiation \\
$\phi:$ & Constraint factor & $\alpha, \eta$, and $\gamma:$ & Equation constants used for \\
$c:$ & Sum of the length of the crack and half the & & Vickers indentation \\
& $\quad$ indentation diagonal in the same direction & $P_{\mathrm{L}}{ }^{*}:$ & Load for lateral crack initiation \\
$a:$ & Length of the indentation diagonal & $\xi:$ & Dimensionless constant \\
$H:$ & Hardness & CPSP: & Critical plasma spray parameter \\
$\beta:$ & Constant for ceramic material & SOD: & Standoff distance \\
$d_{\mathrm{c}}:$ & Critical depth & &
\end{tabular}

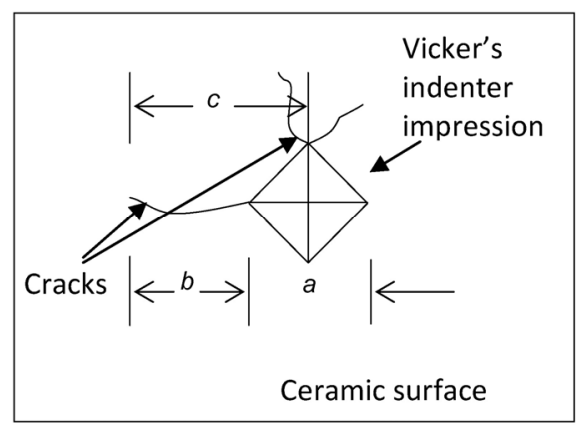

Fig. 1 Schematic of fracture toughness calculation using a Vickers indenter.

It is well established that there exists a critical depth of penetration on a ceramic surface, beyond which the material removal changes from the ductile regime to brittle fracture. This critical depth required for the ductile to brittle transition is given as follows [10]:

$$
d_{\mathrm{c}}=\beta\left(\frac{E}{H}\right)\left(\frac{K_{\mathrm{IC}}}{H}\right)^{2}
$$

where $\beta \approx 0.15$ for ceramics, assuming that the depth of penetration is equal to the machine infeed, $E$ is the elastic modulus of the coating (in GPa), $H$ is the hardness (in GPa), and $K_{\mathrm{IC}}$ is the fracture toughness of the chromia coating (in $\mathrm{MPa} \cdot \mathrm{m}^{1 / 2}$ ).

Further, in ceramic materials, the critical loads for radial and transverse cracks in ceramics and ceramic coatings (Fig. 2) can be obtained from the following expressions [11, 12]:

(a) Critical load for radial crack initiation:

$$
P_{\mathrm{R}}^{*}=54.5\left(\frac{\alpha}{\eta^{2} \gamma^{6}}\right)\left(\frac{K_{\mathrm{IC}}{ }^{4}}{H^{3}}\right)
$$

(b) Critical load for lateral crack initiation:

$$
P_{\mathrm{L}}^{*}=\xi\left(\frac{K_{\mathrm{IC}}^{4}}{H^{3}}\right) f\left(\frac{E}{H}\right)
$$

where $\alpha, \eta$, and $\gamma$ are constant, and for the Vickers indenter, $\alpha=2 / \pi, \eta \approx 1$, and $\gamma=0.2$. $\xi$ is a dimensionless constant, $f(E / H)$ is an attenuation function equivalent to $2 \times 10^{5}$ [12]. Figure 2 shows the formation of radial and transverse cracks during indentation.

The present work was undertaken to study the effects of the parameters of the spray process, i.e., the variation in stand-off distance (SOD) and critical plasma spray parameter (CPSP), on the coating propertiesespecially the fracture toughness. The CPSP value is given as follows:

$$
\mathrm{CPSP}=\frac{\text { Input power }}{\text { Primary gas flow rate }(\mathrm{slpm})}
$$

It is expected that the ensemble of results obtained using the same set of equipment and instruments will be useful to thermal spray industries.

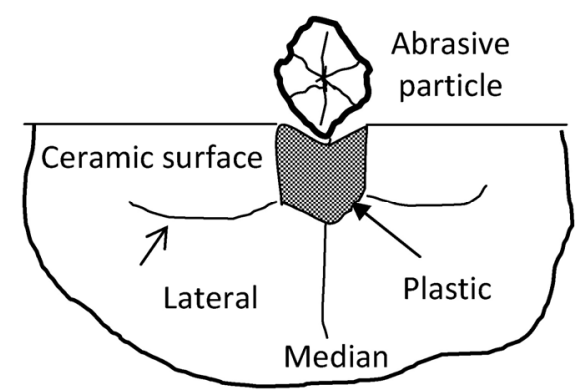

Fig. 2 Crack propagation in a brittle material (e.g., ceramic/ ceramic coating) [13]. 


\section{Experimental procedure}

The chromia coatings were sprayed on mild steel samples using the METCO 9MB gun and 9MC spray system. At first, the steel substrates were ground and ultrasonically cleaned. Grit blasting was performed on one of the surfaces prior to the coating. This was followed by the deposition of the bond coat. Nickelaluminum was used for this purpose. Finally, the top coat was deposited over the bond coat. Table 1 lists the spray parameters used for the preparation of the coating. The SOD and CPSP values were varied uniformly to study their effect on the coating properties.

The coating hardness was measured using a hardness tester (LECO LM700, USA) and an average of ten hardness readings was considered for each coating. The porosity of the top coat was measured from the images of the cross sections using AxioVision image analysis software. The porosity calculation is performed using the principle of gray value analysis [14]. The surface roughness of the coating was measured using a contact-type surface roughness tester (Taylor-Hobson Surtronic 3+, UK). The sampling length for the roughness evaluation was set to $4 \mathrm{~mm}$., For the study of the coating cross sectional, a scanning electron microscope (SEM) (Zeiss EVO 18, Germany) and an optical microscope (Zeiss Axio Vert.A1, Germany) were used. Indentations were also made on the sample cross sections under a load of $1.962 \mathrm{~N}(\approx 200$ gf) using a micro-hardness tester (MVH-S-AUTO, Omnitech, India). The purpose of these indentations was to generate cracks for the measurement of the indentation fracture toughness. The cracks and diagonal lengths were measured using Axio Vision (Zeiss, Germany) and Image-J (NIH, USA) software. Depth sensing indentations were performed using an instrumented hardness tester (Micro-combi tester, CSM instruments,

Table 1 Spray parameters.

\begin{tabular}{ccccc}
\hline Coating & $\begin{array}{c}\text { CPSP } \\
(\mathrm{V} \times \mathrm{I} / \mathrm{F} . \mathrm{R})\end{array}$ & $\begin{array}{c}\mathrm{SOD}^{*} \\
(\mathrm{~mm})\end{array}$ & $\begin{array}{c}\text { Powder } \\
\text { flow rate } \\
(\mathrm{g} / \mathrm{min})\end{array}$ & $\begin{array}{c}\mathrm{N}_{2} / \mathrm{H}_{2} \\
\mathrm{slpm}\end{array}$ \\
\hline $\mathrm{Cr}_{2} \mathrm{O}_{3}$ & $1504: \mathrm{C} 1$ & $100: \mathrm{S} 1$ & & \\
$(-125+11)$ & $1655^{*}: \mathrm{C} 2$ & $120^{\#}: \mathrm{S} 2$ & 55 & $23.6 /$ \\
crushed & $1805: \mathrm{C} 3$ & $140: \mathrm{S} 3$ & & \\
\hline
\end{tabular}

* Standard CPSP for all SOD

\# Standard SOD for all CPSP
Switzerland) equipped with a Vickers indenter. The indentation measurements were undertaken under a maximum load of 2,000 $\mathrm{mN}$, loading and unloading rate of $4,000 \mathrm{mN} / \mathrm{min}$, and with a dwell time of $15 \mathrm{~s}$ [15]. In order to evaluate the coating strength, scratch tests were conducted on the surface of the ceramiccoated samples using a Ducom scratch tester TR-101-M5 (Ducom, USA). The scratch tests were performed with an initial load of $10 \mathrm{~N}$ that gradually increased till it reached $80 \mathrm{~N}$ to obtain a scratch length of $7 \mathrm{~mm}$. The scratch velocity was fixed at $0.1 \mathrm{~mm} / \mathrm{s}$.

\section{Results and discussion}

Figure 3 shows the SEM images of the cross section of the chromia coatings. It reveals that for a low CPSP, the porosity is high and the partially melted region (PMR) is small; at a recommended value of the CPSP, these defects are diminished; and at higher values of the CPSP, the PMR grows while the porosity decreases. The melting point of chromia is approximately $2,435^{\circ} \mathrm{C}$. At a high value of the CPSP, the plasma is aggressive in nature. A fraction of ceramic particles, chiefly the particles with the smallest diameter, was unable to penetrate the plasma and pass through the neighboring trajectory. These particles absorb a portion of the plasma heat and form a partially melted region, as shown in Fig. 3. Partially melted regions appear when the particle dwell time in the plasma is insufficient for a group of ceramic particles to melt. Similarly, at smaller SODs, the porosity is low but the PMR is high, and as the SOD increases, the PMR reduces but the porosity increases. This is attributed to the coarse and wide distribution of the chromia particles, which contributes to non-uniform melting during the plasma spraying process [16].

The magnitudes of the coating defects for the corresponding variations are given in Table 1. The elastic moduli of the plasma sprayed coatings that were sprayed at the recommended value of the CPSP or SOD is the highest as compared to maximum and minimum values of parameters taken into consideration (refer Fig. 2). This can be attributed to the higher melting proportion and less coating defects as compared to coatings obtained from other parametric combination of CPSP and SOD (Table 1). However, the 

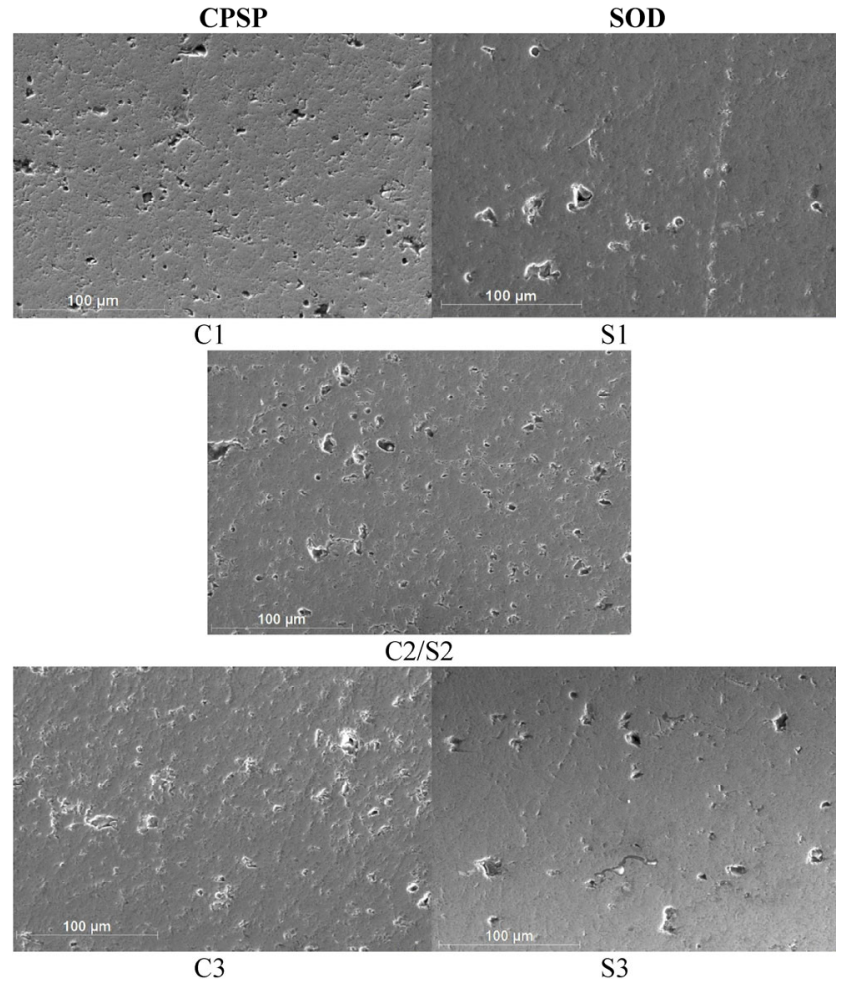

Fig. 3 SEM images of cross section of chromia coating at $1000 \mathrm{x}$ for listed parametric variations.

measured fracture toughness (using Eq. (1)) showed an increasing trend with the increase in the CPSP and a slight variation with a change in the SOD. This is attributed to improved melting and the densification of the coating. The hardness of the coating varies proportionally with the increase in CPSP. However, at maximum SOD, the hardness decreased and this is attributed to the increase in porosity content of the coating. Figure 4 shows the variation in the mechanical

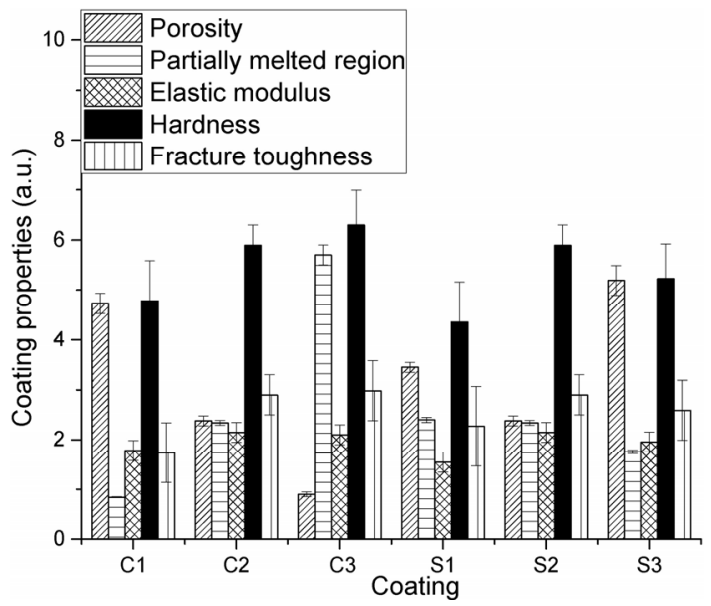

Fig. 4 Relative comparison of mechanical properties of chromia coatings. properties of the sprayed chromia coating with respect to the change in the CPSP and SOD.

The coating with the recommended value of the CPSP and SOD exhibited the best results while the coating with the lowest value of the CPSP and lowest SOD had a poor structure. Table 2 lists the percentage content of the porosity and partially melted region present in the chromia coating.

Coatings sprayed at the lowest value of the CPSP and the highest SOD had the maximum porosity, while coatings sprayed at the maximum value of the CPSP and lowest SOD had the highest percentage of partially melted region. The increase in the porosity is attributed to unmelted particles becoming embedded in the coating and the shadowing effect of the splats. Moreover, at the maximum value of the CPSP, a portion of the chromia powder of smaller particle size could not penetrate the plasma plume and flew close to the plasma, thus absorbing a part of the plasma heat. This led to the formation of a partially melted region. Moreover, at the minimum SOD, the particle dwell time was insufficient for converting the particle to the liquid state before it struck the substrate. This led to an increase in the partially melted region.

Figure 5 shows the optical images of the indentation marks on the coating surface. Owing to the heterogeneous properties of the coating due to the porosity and the presence of partially melted regions, the indentation caused the crumbling of subsequent layers from the surface. More of this crumbling was observed in the case of the coating with the lowest value of the CPSP.

As shown in Fig. 6, the X-ray diffraction of the coating indicated the stress-induced crystalline structure of the chromia at a high value of the CPSP and a low SOD. A small amount of the amorphous phases are

Table 2 Measured morphology and properties of chromia coating.

\begin{tabular}{ccccccc}
\hline Coating & $\begin{array}{c}\text { Porosity } \\
(\text { Area \%) }\end{array}$ & $\begin{array}{c}\text { PMR } \\
(\text { Area \%) }\end{array}$ & $\begin{array}{c}E \\
(\mathrm{GPa})\end{array}$ & $\mathrm{HV}_{200}$ & $\begin{array}{c}K_{\mathrm{IC}} \\
\left(\mathrm{MPa} \cdot \mathrm{m}^{-1 / 2}\right)\end{array}$ & $\begin{array}{c}d_{\mathrm{c}} \\
(\mu \mathrm{m})\end{array}$ \\
\hline $\mathrm{C} 1$ & 4.73 & $<1$ & 178.14 & 957.1 & 1.74 & 0.0978 \\
$\mathrm{C} 2 / \mathrm{S} 2 *$ & 2.38 & 2.34 & 214.97 & 1179 & 2.9 & 0.1755 \\
$\mathrm{C} 3$ & $<1$ & 5.70 & 209.81 & 1259 & 2.98 & 0.1484 \\
$\mathrm{~S} 1$ & 3.45 & 2.4 & 155 & 871 & 2.27 & 0.1922 \\
$\mathrm{~S} 3$ & 5.19 & 1.76 & 195.42 & 1045 & 2.59 & 0.1826 \\
\hline
\end{tabular}

* $\mathrm{C} 2=\mathrm{S} 2$ (i.e., $\mathrm{C} 2$ and $\mathrm{S} 2$ parameters are identical) 


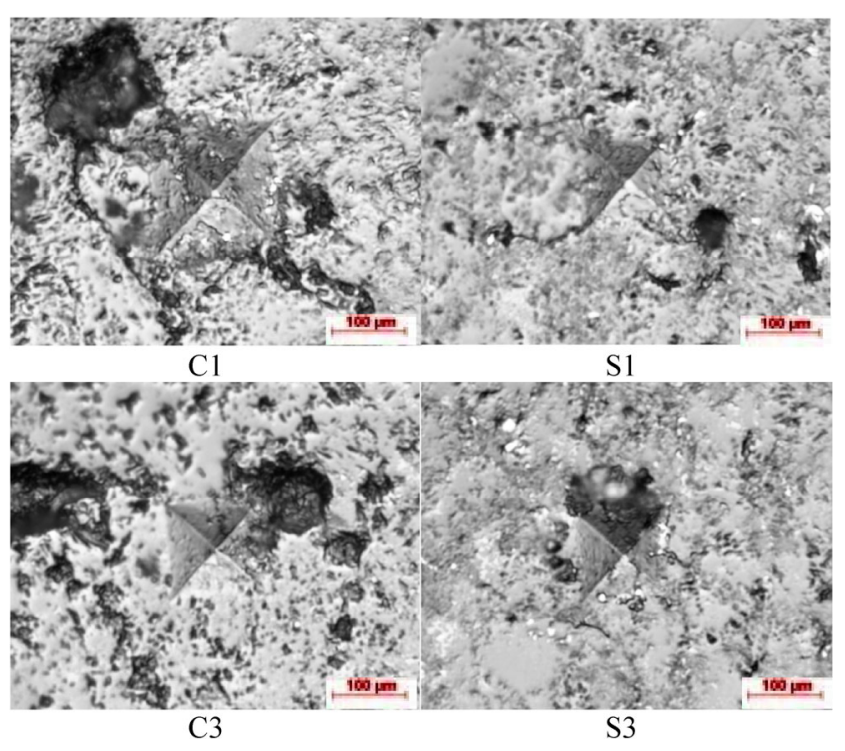

Fig. 5 Optical image of Vickers indentation taken at cross section of the chromia coatings.
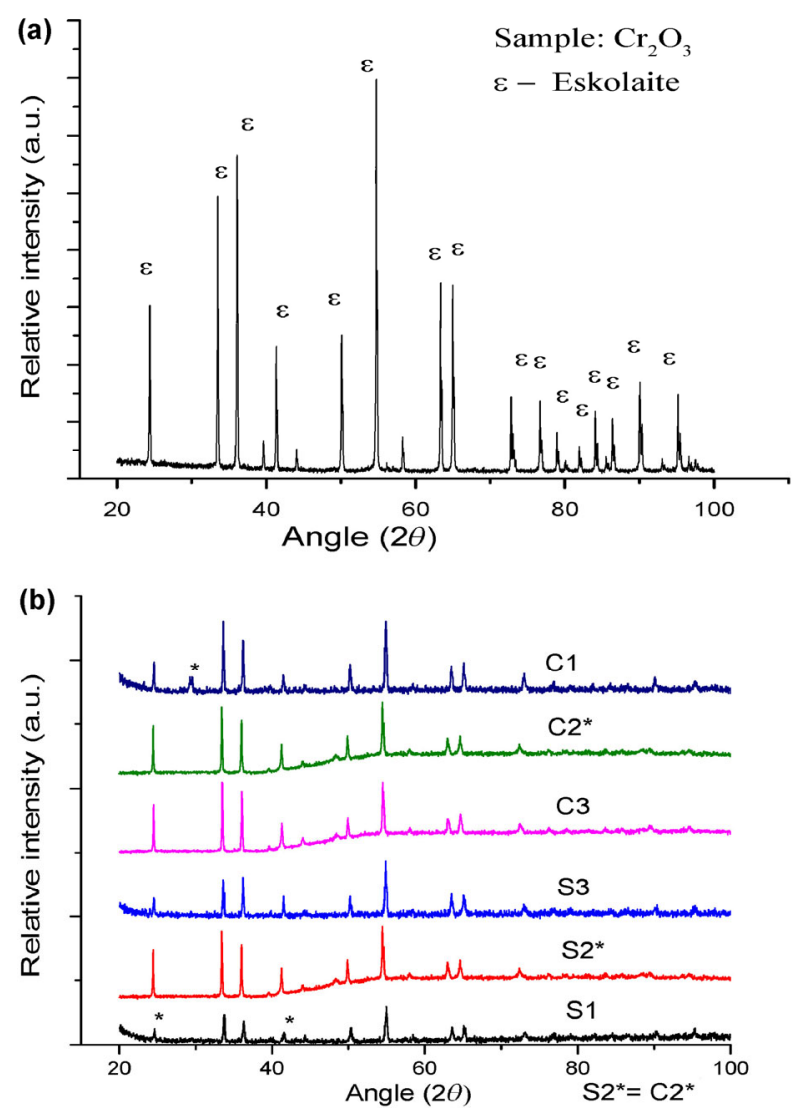

Fig. 6 X-ray diffraction of (a) chromia powder and (b) chromia coating at five parametric variations.

also observed in coatings at high value of the CPSP and low SOD. In contrast, a low value of the CPSP leads to a partial transformation of the phases. This is attributed to the inability of the chromia particles to penetrate the plasma plume at a high value of the CPSP.

Similarly, at a low SOD, the melting time of the particles is reduced and partially melted regions come into existence. At a low value of the CPSP, the available plasma heat is insufficient for the complete melting of the chromia particles. Consequently, both partially melted and unmelted particles become embedded with the molten splats, thus forming a heterogeneous coating structure.

In chromia coatings, the radial and lateral cracks are likely to occur at loads that can be obtained using Eqs. (3) and (4), as previously explained. In ceramic coatings, abrasion or erosion wear occur primarily owing to brittle fracture. When the cracks nucleate and converge, material is removed from the surface and chipping occurs. Figure 7 shows the variation in the critical load for the crack formation in chromia coatings for various coating parameters. It is observed that the load-carrying capacity without crack formation is highest in the case of the chromia coating sprayed at the recommended CPSP and SOD. An increase or decrease in CPSP/SOD resulted in low resistance to crack formation. Variations in the SOD produced a slight change in the critical load while variations in the CPSP caused a noticeable deviation. This is attributed to the difference in the coating fracture toughness and hardness. The coating hardness and toughness values are the highest in the case of the chromia coating sprayed at the recommended parameters.

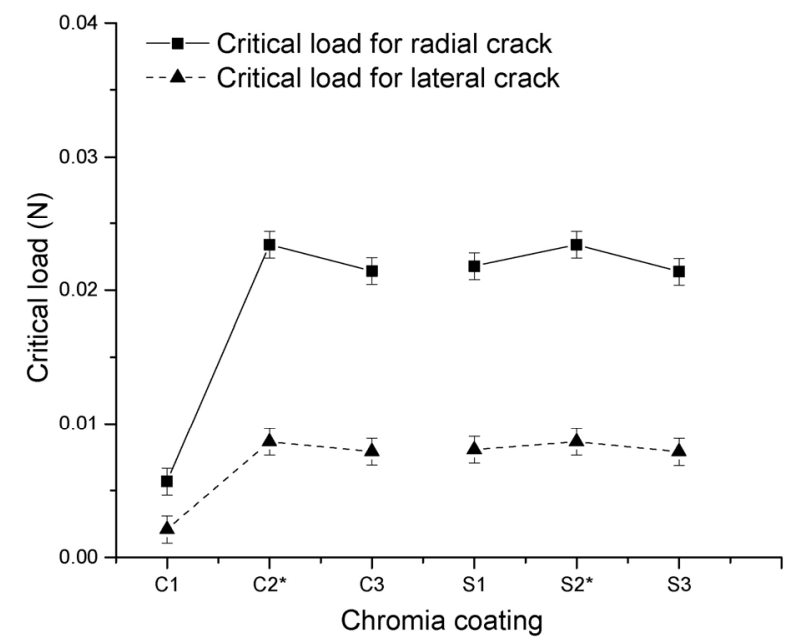

Fig. 7 Variation of critical load with respect to parameters of chromia coating. 
In order to study the coating performance when subjected to gradual loading, scratch tests were performed on the coating surface. The nature of the scratch surface largely depends upon the critical depth, as explained earlier. The corresponding critical depth for each coating is given in Table 2. Figure 8 shows the load versus displacement curve obtained from the scratch test. It is observed that, except for the recommended parameters, the chromia coatings completely failed even for small loads. The porosity was the major contributor to the erratic failures of the coating. The scratch debris consisted of fragmented chips, thus indicating that the failure occurred primarily owing to micro-brittle fracture. Initially, at a low load, the scratch indenter depth is less than the critical depth of the coating. This resulted in some degree of plastic deformation followed by failure due to spalling. This effect was reported by Zhang et al. [17] in their work on plasma sprayed $\mathrm{Al}_{2} \mathrm{O}_{3}$ coatings. However, at higher loads, the ploughed surface showed signs of brittle fracture along with fragmented chips. Figures 9(a)-9(b) shows the gradual transition of the ductile mode of the material removal to brittle fracture as the load of the scratch indenter gradually increased.

\section{Conclusions}

The chromia powder can be successfully coated using an air plasma spray system. For spraying, the optimized spray parameters are necessary to obtain the desired mechanical properties. On increasing the arc current, higher values of the CPSP lead to an increase in the partially melted regions while low values of the CPSP lead to high porosity. Moreover, a large SOD leads to early solidification of the molten ceramic droplets before they reach the substrate. This results in an increase in the porosity of the coating. The mechanical properties such as the hardness, fracture toughness, and Young's modulus largely depend on the coating density. The increase in the porosity reduces the effective hardness and coating toughness. However, the occurrence of the partially melted region results in a slight change in the coating toughness and hardness. The critical load required for crack initiation was determined for all the coatings, and it was observed that this load largely depends on the CPSP rather than the SOD. Finally, the indentation scratch tests performed on the coating specimens revealed that the failure of the plasma sprayed coating
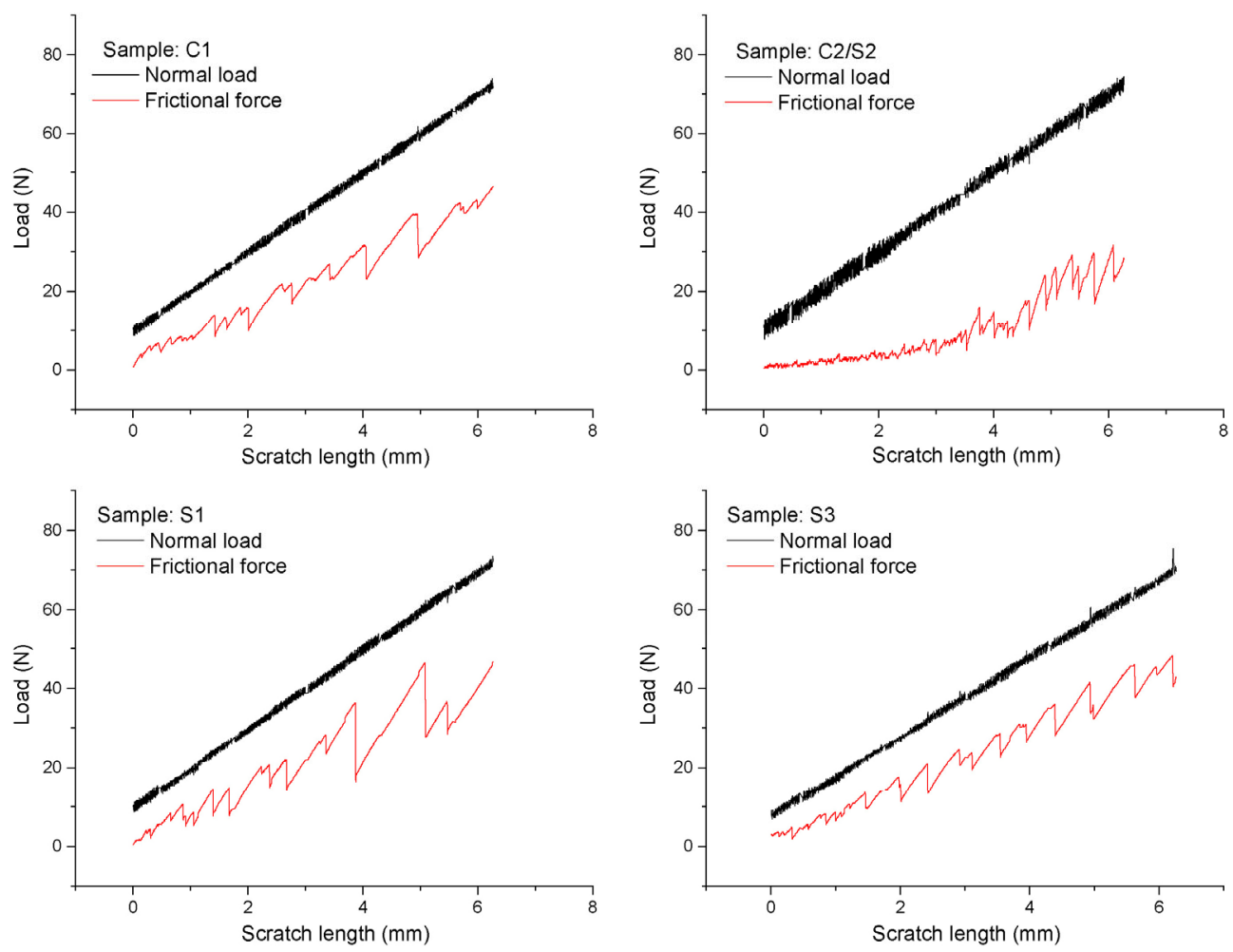

Fig. 8 Load versus displacement curve of coating performance during scratch test. 
(a)

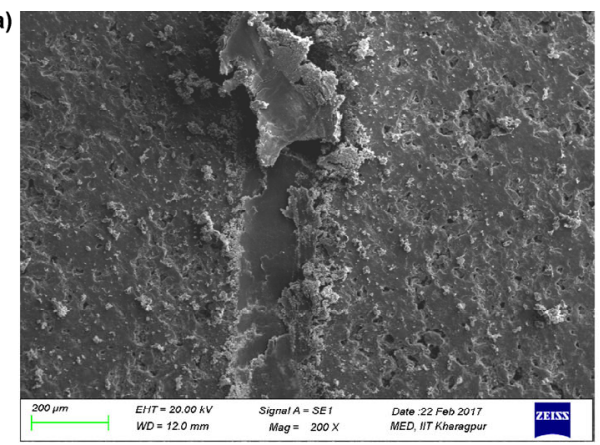

(c)

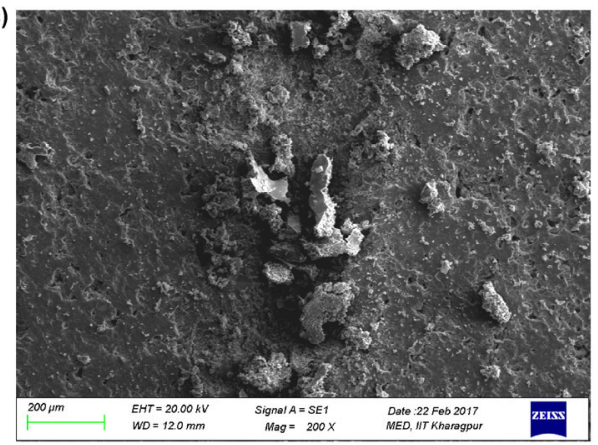

(b)

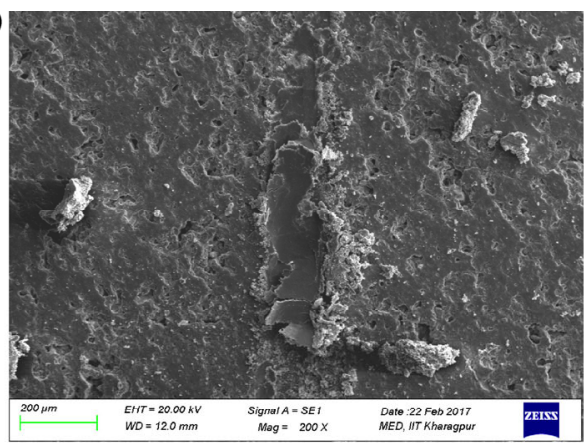

(d)

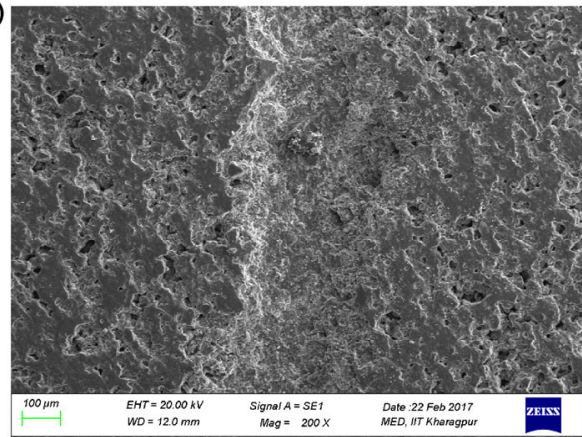

Fig. 9 SEM images of scratched surface at various loads.

that was sprayed at the recommended CPSP, occurred at a higher load. Further, any variation in CPSP or SOD contributed to weak adhesion between chromia coating and the metallic substrate.

\section{Acknowledgments}

The authors are extremely grateful to Prof. Mihir Sarangi, IIT Kharagpur for providing his research facilities. Authors also acknowledge the MHRD, Govt. of India for the financial support.

Open Access: The articles published in this journal are distributed under the terms of the Creative Commons Attribution 4.0 International License (http:// creativecommons.org/licenses/by/4.0/), which permits unrestricted use, distribution, and reproduction in any medium, provided you give appropriate credit to the original author(s) and the source, provide a link to the Creative Commons license, and indicate if changes were made.

\section{References}

[1] Halling J. Principles of Tribology. London (UK): Macmillan Education, 1978.
[2] Cetinel H, Celik E, Kusoglu M I. Tribological behavior of $\mathrm{Cr}_{2} \mathrm{O}_{3}$ coatings as bearing materials. J Mater Process Technol 196(1-3): 259-265 (2008)

[3] Wang B Q, Shui Z R, Levy A V. Sliding wear of thermalsprayed chromia coatings. Wear 138(1-2): 93-110 (1990)

[4] Heimann R B. Plasma Spray Coating: Principles and Applications. 2nd ed. Weinheim (Germany): Wiley-VCH, 2008: 1-427.

[5] Pawlowski L. Technology of thermally sprayed anilox rolls: State of art, problems, and perspectives. $J$ Therm Spray Technol 5(3): 317-334 (1996)

[6] Pawlowski L. The Science and Engineering of Thermal Spray Coatings. Chichester (UK): Wiley, 1995.

[7] Lawn B R, Evans A G, Marshall D B. Elastic/plastic indentation damage in ceramics: The median/radial crack system. J Am Ceramic Soc 63(9-10): 574-581 (1980)

[8] Callister W D Jr. Fundamentals of Materials Science and Engineering: An Integrated Approach. New York (USA): John Wiley \& Sons, 2001.

[9] Evans A G, Charles E A. Fracture toughness determinations by indentation. J Am Ceramic Soc 59(7-8): 371-372 (1976)

[10] Bifano T G, Dow T A, Scattergood R O. Ductile-regime grinding: A new technology for machining brittle materials. J Eng Ind 113(2): 184-189 (1991)

[11] Zhang D, Li C, Jia D, Wang S, Li R, Qi X. Grinding model and material removal mechanism of medical nanometer zirconia ceramics. Recent Pat Nanotechnol 8(1): 2-17 (2014) 
[12] Lawn B R, Evans A G. A model for crack initiation in elastic/plastic indentation fields. J Mater Sci 12(11): 21952199 (1977)

[13] Beshish G K, Florey C W, Worzala F J, Lenling W J. Fracture toughness of thermal spray ceramic coatings determined by the indentation technique. $J$ Therm Spray Technol 2(1): 35-38 (1993)

[14] Du H, Shin J H, Lee S W. Study on porosity of plasmasprayed coatings by digital image analysis method. $J$ Therm Spray Technol 14(4): 453-461 (2005)

[15] Bandyopadhyay P P, Chicot D, Venkateshwarlu B, Racherla

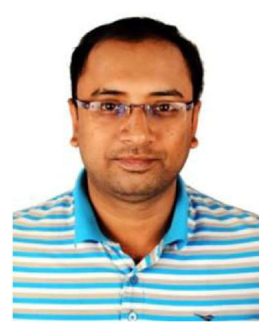

Simanchal KAR. He is a Ph.D student in the Department of Mechanical Engineering at Indian Institute of Technology Kharagpur. He received his B.Tech and M.Tech

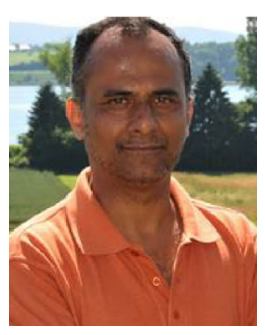

Partha Pratim BANDYOPADHYAY. He received his M.Tech and Ph.D degrees in mechanical engineering from IIT Kharagpur, India, in 1992 and 2000, respectively. He is currently attached to IIT Kharagpur as a pro-

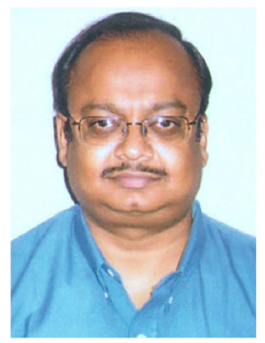

Soumitra PAUL. He received his M.Tech and Ph.D degrees in mechanical engineering from IIT Kharagpur, India, in 1989 and 1994, respectively. He is attached to IIT Kharagpur as a professor of mechanical engineering. His research
V, Decoopman X, Lesage J. Mechanical properties of conventional and nanostructured plasma sprayed alumina coatings. Mech Mater 53: 61-71 (2012)

[16] Kar S, Paul S, Bandyopadhyay P P. Processing and characterisation of plasma sprayed oxides: Microstructure, phases and residual stress. Surf Coat Technol 304: 364-374 (2016)

[17] Zhang J, Chen H, Lee S W, Ding C X. Evaluation of adhesion/cohesion of plasma sprayed ceramic coatings by scratchtesting. In Thermal Spray 2007: Global Coating Solutions: Proceedings of the 2007 International Thermal Spray Conference, ASM International, 2007: 472-477.

degrees in mechanical Engineering in 2006 and 2011 from KIIT University, Bhubaneswar, India.

His research interests include abrasive machining process, thermal spray processes, and material characterization.

fessor of mechanical engineering.

His research interests include CNT or diamond particulate reinforced coatings, micro and nano finishing of thermally sprayed coatings, laser treatment of coatings, etc.

interests include machining, grinding, cutting tool coating, thick coating, finishability of thick coatings, high speed grinding of ceramics and carbon fibre ceramic matrix composites, high speed grinding of aerospace materials, minimum quantity lubrication in machining and grinding, micro machining, etc. 